\title{
EL REY Y LAS FUERZAS ARMADAS
}

POR

MIGUEL HERRERO DE MIÑON

Letrado del Consejo de Estado

\section{INTRODUCCION}

Una Constitución normativa es aquella que, como toda norma, tiene una pretensión de validez, es decir, espera regir la parcela de la realidad social a la que sus preceptos se dirigen, en este caso el proceso político. Esto es lo que afirma taxativamente el artículo 9 de nuestra Constitución al declarar que, tanto los ciudadanos como los poderes públicos, «están sujetos a la Constitución». Por.ello, el desarrollo constitucional, categoría no demasiado frecuente y que en nuestro país ha sufrido una inflación de todo tipo, incluso con reflejos buroctáticos, ha de manejarse con cuidado para que el supuesto desarrollo legislativo de la Constitución no sustituya a la Constitución misma, reduciendo ésta a una serie de enunciados retóricos de validez nominal y llevando al máximo el fenómeno de las «brechas» constitucionales, es decir, del vaciamiento de la normativa constitucional por las normas de aplicación de la misma ${ }^{1}$.

Este carácter prioritario de la aplicación de la Constitución debe predicarse tanto de su parte dogmática, sin perjuicio de distinguir los diversos lenguajes en ella utilizados ${ }^{2}$ y el carácter preceptivo o indicativo de sus disposiciones, como de su parte orgánica, y amenazan con abrir peligrosas brechas a la Constitución tanto aquellas disposiciones que al regular el ejercicio de un derecho vaciaran su contenido como aquellas otras que no respetasen la distribución de competencias establecidas en la parte orgánica.

En el campo de los derechos y libertades, la sensibilidad social y la cláusula de salvaguarda del contenido esencial de los mismos (art. 53) es una garantía doble de esa «enérgica pretensión de validez» propia de la Constitución en un Estado de Derecho. Por el contrario, la parte orgánica de la Constitución, instrumento fundamental para realizar los valores de la parte dogmática, se encuentra mucho menos protegida, tanto porque las garantías sociales, esto es,

${ }^{1}$ Cf. Löwenstein, Teoría de la Constitución. Traducción española, Barcelona, 1964.

${ }^{2}$ Cf. mi trabajo «En torno a la aplicación de la Constitución», en La Constitución española y las fuentes del Derecho, II, Madrid, 1979, págs. 1232 y sigś. 
la sensibilidad de la opinión pública es menor y está peor formada, como porque las garantías políticas puedan ser dominadas por un malentendido acuerdo de los partidos dominantes, como porque, en fin, las garantías jurídicas no han alcanzado su pleno funcionamiento. Si el Tribunal Constitucional, por una u otra razón, no restableciese el orden así violado, el defecto no se subsanaría, sino que, al contratio, agravaría sus peligrosas consecuencias.

Un buen ejemplo de ello es la reciente Ley Orgánica de la Defensa, por tantas razones encomiable, y que revela profundos conocimientos técnicos de quienes a ella han contribuido, ya desde las Fuerzas Armadas, ya desde la Administración Militar, y que, sin embargo, en un extremo de capital importancia -el desarrollo de las disposiciones constitucionales relativas a la función y dirección de las Fuerzas Armadas - se aparta de aquellos principios de la Constitución a los que, según el artículo 8 de la misma, debía ajustarse estrictamente.

Los tres preceptos fundamentales al respecto son: en primer lugar, el artículo $8 .^{\circ}$ de la Constitución, según el cual

«Las Fuerzas Armadas... tienen como misión garantizar la soberanía e independencia de España, defender su integridad territorial y el ordenamiento constitucional» (art. 8.1).

Es decir, se señala la doble función, exterior e interior, de los Ejércitos. En segundo lugar, el artículo 62, según el cual das»,

«Corresponde al Rey: h) el mando supremo de las Fuerzas Arma-

y el artículo 97, que dispone:

«El Gobierno dirige... la administración militar y la defensa del Estado.»

Para la interpretación de estos preceptos ha de atenderse, por un lado, a lo dispuesto en el artículo 56, según el cual

«El Rey... ejerce las funciones que le atribuyen expresamente la Constitución y las leyes»,

y, por otro, el artículo 64 , según el cual

«Los actos del Rey serán refrendados por el presidente del Gobierno $\mathrm{y}$, en su caso, por los ministros competentes. den.»

De los actos del Rey serán responsables las personas que lo refren-

La interpretación sistemática de estos preceptos, exigida por el artículo 3 del Código Civil, ha de permitir construir las categorías necesarias para obtener 
una interpretación coherente de todo el conjunto, sólo posible en un contexto decantado por el Derecho comparado.

Para comprobarlo analizaré, en primer lugar, la función constitucional del jefe del Estado con relación a las Fuerzas Armadas en el moderno Derecho comparado (I); después, la solución esbozada en la reciente legislación española (II) y cómo se compadece con la función de las Fuerzas Armadas como garante político de la Constitución (III).

\section{PANORAMA COMPARADO}

Tradicionalmente el jefe del Estado, en el régimen constitucional, es jefe de las Fuerzas Armadas. Ello bien porque la Constitución otorgada por el rey absoluto cede a terceros competencias de las que se excluyen aquellas más caras al poder soberano, bien porque la Constitución elaborada por asambleas representativas desde una óptica racionalista considera el poder militar inherente al ejecutivo, siguiendo las pautas de Locke y Montesquieu. Tal es hoy día la panorámica del Derecho constitucional comparado occidental, tanto en las monarquías como en las repúblicas, con la sola excepción entre las primeras de Japón y Suecia, donde, por razones muy diferentes, la jefatura de las Fuerzas Armadas se atribuye al jefe del Gobierno parlamentario como titular no sólo efectivo, sino incluso nominal del poder ejecutivo ${ }^{3}$.

Sin embargo, la posición del jefe del Estado en relación con los ejércitos puede ser ya de jefatura honorífica, ya de jefatura efectiva. En el primer caso, como rezaba la Constitución francesa de 1946, el presidente de la República «ostenta el título de jefe de las Fuerzas Armadas», y este mero título no empece en absoluto que el mando sea ejercido bien por el Gobierno, bien por terceros, aunque esta misma denominación, en apariencia reducida a un mero título de honor, fue utilizada como base de intervenciones presidenciales ante las Fuerzas Armadas en las crisis finales de la IV República francesa ${ }^{4}$.

Por otro lado, el jefe del Estado puede ser jefe efectivo de las Fuerzas Armadas y ostentar de manera no nominal, sino real, el mando supremo de las mismas. Sin duda, el ejercicio de este mando supremo será susceptible de modalidades muy diversas, según el sistema político constitucional dentro del que dichas competencias hayan de ejercerse y según también los factores técnicos que determinen las posibilidades de acción militar.

No es lo mismo mando supremo que mando absoluto. Si el supremo mando militar en un régimen de total hipertrofia del poder, como fue el del III Reich, suponía competencias absolutas, no ocurre lo mismo en un sistema constitucional. Así, mientras que en un sistema semipresidencial como el francés las competencias militares del presidente de la República se ejercen con amplia discrecionalidad bajo el refrendo de un Gobierno apoyado por la doble confianza del jefe del Estado y del Parlamento, en una monarquía parlamentaria como la belga dichas competencias se ejercen por el rey bajo el refrendo de un

${ }^{3}$ Cf. los datos de Derecho comparado en Bergotini, La Diffense Nazionale, Milán, 1974.

4 Cf. Bromberger y Elgey, Barricades et Colonels, París, 1960. 
Gobierno estrictamente parlamentario. Sobre todos estos supuestos trataremos más adelante. Por otra parte, la afectividad del mando supremo militar no puede tener el mismo alcance cuando, dado los medios de combate, el rey sólo puede hacer acto simbólico de presencia en el frente y dar apoyo moral a unas tropas, incluso integradas bajo un mando extranjero, que cuando las posibilidades ofrecidas por la fuerza atómica permiten al jefe del Estado, con una sola decisión, comprometer la capacidad de defensa y ataque del país de manera irreversible en una determinada dirección, asumiendo así de hecho, y no sólo de derecho, la más alta responsabilidad del mando estratégico militar.

A su vez, en este mando efectivo caben dos cosas distintas: la dirección política de la guerra y su preparación y la dirección técnica de ambas. En la primera se establece la finalidad política de la preparación y la acción militar, así como las líneas generales de la misma, mientras que la segunda se refiere a los actos de mando relativos a la consecución de objetivos militares concretos. Mientras la primera es una actividad eminentemente política, la segunda es fundamentalmente militar, pero precisamente los actos de alto mando constituyen una forma de dirección política caracterizada por el contenido propio de la actividad militar de las Fuerzas Armadas. Durante la época clásica del Derecho constitucional, el monarca, y en general el jefe del Estado, ejerció en numerosas ocasiones (Napoleón III en 1859, Alberto I en 1914) el mando militar en el sentido no sólo político, sino técnico del término, pero progresivamente se impuso la tendencia a transferir a profesionales el mando técnico, mientras que la dirección política, sin perjuicio de su control por el monarca, se ejercía con participación del Gobierno. Hoy día las condiciones técnicas de la guerra no sólo permiten, sino que exigen la coincidencia del alto mando técnico y la dirección política, al menos en cuanto a las opciones estratégicas capitales se refiere. Ello posibilita de nuevo que quien nominalmente ejerce el alto mando y políticamente está habilitado para ello, como es el caso del jefe del Estado en las condiciones institucionales ya expuestas, pueda además ejercer, como sus más remotos antecesores, el efectivo mando de las operaciones.

Sin embargo, es preciso atender con más detalle a la articulación de potestad política y potestad militar, si es que ha de entenderse el significado de la atribución al jefe del Estado del mando militar supremo, que no es otro que expresar la subordinación de una organización, «por definición obediente», al poder político soberano.

Dos son los modelos que hoy día ofrece la panorámica comparada respecto de esta articulación entre la autoridad militar y el poder político: la autoridad militar como poder autónomo y la autoridad militar como competencias desconcentradas 5 .

La primera solución consiste en la transferencia a los propios militares de la suprema libertad y responsabilidad en la dirección de la defensa y de la guerra y, puesto que es propio del mando castrense el ser único, dicha transfe-

${ }^{5}$ Chantebout, L'Organisation Générale de la Défense Nationale en France depuis la fin de la Seconde Guerre Mondiale, París, 1967, págs. 62 y sigs. 
rencia se realiza en último término en favor de una personalidad militar. Tal es el caso de la obsoleta práctica francesa de designar un generalísimo, legalmente reconocida por la Ley de 11 de julio de 1938. De acuerdo con esta concepción, en tiempo de guerra - y es difícil en nuestros días separar el tiempo de guerra de su preparación y de la endémica violencia que la presideel soldado asume una responsabilidad propia y decide la batalla por sí y ante sí «como él es responsable ante el país y ante el exterior». Tal fue la concepción que, si condujo a la victoria francesa en 1918 merced a Foch, permitió «la insólita derrota» de 1940 al colocar las decisiones políticas en manos de Weygand: Tal fue también, hasta el advenimiento del fascismo, la tradición constitucional italiana, sólo formalmente atenuada por la tradición castrense de los Saboya ${ }^{6}$.

En cuanto autoridad desconcentrada, la función del mando militar es la de aconsejar y ejecutar, pero sin libertad ni responsabilidad en la concepción y dirección de las operaciones militares. Tanto si existe un colegio técnico, caso de la Junta de Jefes de Estado Mayor, como si hay una suprema autoridad de carácter monocrático, se trata siempre de un órgano asesor del poder, con la sola competencia de aconsejar, proponer y ejecutar, pero nunca de decidir ni siquiera en el campo estrictamente militar.

Esta es la solución que ha prosperado allí donde el jefe del Estado, que representa la supremacía de éste, es además el efectivo jefe del ejecutivo. Así ocurría en las viejas monarquías y hoy en los sistemas presidenciales, especialmente en los Estados Unidos, donde el presidente es y actúa como efectivo comandante en jefe ${ }^{7}$. En los sistemas parlamentarios nada empece lógicamente que el presidente del Gobierno ejerza efectivamente esta función de supremo poder militar. Sin embargo, la experiencia de monarquías y repúblicas parlamentarias parece concluir que el Gobierno suele ceder su competencia de re militari a otras instancias, ya políticas - jefe del Estado-, ya castrenses. Ello exige unas breves consideraciones.

Por una parte, el Gobierno parlamentario tiene un agudo sentimiento de su responsabilidad política constantemente exigible por la o las Cámaras, y ello conduce necesariamente a que pretenda eludir dichas responsabilidades, cediendo a terceros la capacidad de decisión, especialmente cuando esta cesión puede revestirse de consideraciones sobre la índole técnica de la materia en cuestión, como es el caso de los temas militares. Por otro lado, es propio del régimen parlamentario, y en general de toda democracia mediatizada, una especie de solidaridad de la clase política subyacente a las diferencias de partido. Esta solidaridad, a la vez que apoya la elusión de responsabilidades, se basa en la marginación de determinadas materias respecto de la contienda partidista y parlamentaria, y una de estas materias es sin duda alguna el Ejército, al que se valifica de apolítico.

Ahora bien, ello obliga a primera vista a concluir que el control político sobre las Fuerzas Armadas es mayor en la democracia que podemos llamar di-

- Pierandrei, La Prerogativa Regia di Comando delle Forze Armate e il suo Esercizio, Roma, 1942.

${ }_{7}$ Cf. May (ed.), The ultimate decision: the President as Commander in Chief, Nueva York, 1960. 
recta (aquella donde los ciudadanos eligen de hecho e incluso de derecho directamente al Gobierno) que en la democracia mediatizada (aquella donde los ciudadanos no eligen directamente al gobernante, sino que éste, o éstos, son designados por los representantes elegidos por aquéllos), porque la primera favorece la monarquización del poder conducente al «principado», entendiendo por tal — con Bertrand De Jouvenel- aquellos regímenes contemporáneos donde el cuerpo político se encuentra regido por una sola cabeza ${ }^{8}$.

El presidente del Gobierno de la IV República francesa, cuya designación era fruto de una coalición parlamentaria muy lejana a la voluntad directa de los ciudadanos, no pudo controlar al Ejército ni, consiguientemente, comprometer a la nación en opciones irreversibles. Otro tanto puede decirse del primer ministro de la V República, aunque en este caso su mediatización parlamentaria se encuentre doblada por una mediatización presidencial. Por el contrario, el elegido de la nación es el único capaz de optar en materias y trances donde la vida y la muerte están en juego. Así, refiriéndose al presidente de la República francesa, elegido por sufragio universal desde 1962, pudo y puede afirmarse que «el jefe del Estado decide en exclusiva sobre el empleo de la fuerza nuclear estratégica». Por tanto, «en un régimen democrático el jefe del Estado no puede ser elegido por algunos parlamentarios, sino por el conjunto de la nación a la que puede conducir a situaciones dramáticas» ${ }^{9}$.

Ello explica también por qué en aquellos casos donde el parlamentarismo ha evolucionado a sistemas de «principado», apoyado en una democracia directa de hecho, el jefe del Gobierno elegido por la nación tenga las más altas y decisivas competencias militares. Tal es el caso de la Gran Bretaña, donde el primer ministro, único competente para adoptar la opción nuclear, tiene una posición y, por tanto, una responsabilidad y unas competencias al menos parcialmente equivalentes al presidente de la República francesa ${ }^{10}$.

Sin embargo, el análisis de la práctica británica demuestra que las mismas competencias militares del primer ministro se encuentran inhibidas por las de la Corona, dando así una realidad política al concepto jurídico según el cual las competencias militares del Gobierno son siempre ejercicio de la prerrogativa regia, estando amparadas, por tanto, por su misma inviolabilidad. Así, en 1914 los oficiales británicos en Irlanda se niegan a recibir órdenes del Gobierno y es la intervención regia la que les lleva a la disciplina, a la vez que consigue la exclusión del Ulster del Home Rule irlandés; durante toda la guerra del catorce, el comandante en jefe británico, mariscal Haig, depende más del rey que del primer ministro, hasta el punto de que éste ha de apoyar la jefatura interaliada del francés Foch para someter al militar escocés, y si esta situación se obvia durante la Segunda Guerra Mundial por el acuerdo permanente entre Jorge VI y su primer ministro Winston Churchill, todo parece indicar que fue la soberana quien impidió en 1965 el envío de tropas británicas a Rodhesia. Intervenciones semejantes pueden encontrarse en las monarquías escandinavas, espe-

\footnotetext{
8 De Jouvenel, Du Principat, 1964. Recogido en Du Principat et autres reflexions politiques, París, 1972, págs. 131 y sigs., espec. pág. 133.

9 Chantebout, loc. cit., págs. 194 y sigs. Cf. Huvlot en Revue de la Defense Nationale, agosto-septiembre 1973, págs. 29-40.

10 Bergotini, loc. cit.
} 
cialmente en la sueca, aunque matizadas por el apartamiento de este país de los dos últimos conflictos mundiales ${ }^{11}$.

En general, por tanto, cabe afirmar con Prelot que los modernos reyes constitucionales, a más de diplomáticos, son soldados. ¿Por qué? Sin duda han de tenerse en cuenta mecanismos afectivos importantes como la tradición, la formación y la vocación dinástica y personal; pero, a mi juicio, son más decisivos y también más válidos a la hora de propugnar no sólo explicaciones, sino también soluciones, motivos de lógica institucional.

Un jefe elegido, especialmente a través de un sistema de partidos, es siempre un jefe parcial. Si la V República francesa ha podido evitar esta conclusión y realizar una verdadera restauración monárquica en forma electiva ${ }^{12}$, ello se debe a la legitimidad carismática de su primer presidente y al sistema de elección directa y mayoritaria de sus sucesores, independizados, al menos aparentemente, de una candidatura partidista. En Francia el presidente de la República es el elegido por toda la nación, y todos los ciudadanos pueden ver en él - afirmaba el presidente Pompidou- su representante ${ }^{13}$. Por el contrario, cuando el jefe del ejecutivo es por definición el jefe de una mayoría partidista, no puede pretender el mismo grado de representatividad nacional, y ello es especialmente cierto cuando el presidente del Gobierno no es ni siquiera el jefe de la mayoría, sino el dirigente de una coalicción de diversas fracciones por definición minoritarias.

Sobre una situación así, que es la propia de los regímenes parlamentarios, especialmente de aquellos que no cuentan con un fuerte partido mayoritario, es donde incide con especial vigor la capacidad del monarca hereditario, ajeno a los partidos, para representar a la nación en aquellas materias donde se pone, incluso físicamente, en tela de juicio su propia existencia, esto es, tanto en la guerra como en su preparación.

La práctica belga en la materia constituye un clarificador ejemplo del caso ${ }^{14}$. El parlamentarismo mayoritario que se desarrolla de 1846 a 1916, con el turno pacífico de los partidos, no impide que el rey ejerza una importante influencia en materias de defensa, hasta el punto de asumir en 1914 el mando en jefe del Ejército combatiente, sin perjuicio de que todos sus actos estuvieron cubiertos por la responsabilidad ministerial. Es la triunfal experiencia de Alberto I la que potencia la función militar de la Corona en su reinado y en el de su sucesor Leopoldo III, pero a ello contribuye poderosamente la desaparición desde 1919 de sólidas mayorías parlamentarias sustituidas por gabinetes de coalición apoyados en ocasionales y precarias mayorías en desacuerdo sobre las cuestiones fundamentales. El carácter principal de estos gabinetes ministeriales es su carencia de solidaridad y unidad interna $y$, por tanto, la falta de un formal liderazgo en los mismos. En una situación semejante crece la importancia de la función integradora de la monarquía, cuyo

${ }^{11}$ Los datos citados se encuentran en Nicolson, George V, Londres, 1967; WheelerBennett, George VI, Londres, 1958, y Smith, Constitutional and Administrative Law, 1971, página 207 , nota 12 .

${ }_{12}$ Decherf, L'Institution de la Monarcbie dans l'esprit de la $V^{e}$ Republique, París, 1979.

${ }^{13}$ Le Noeud Gordien, París, 1974.

${ }^{14}$ Fusilier, Les Monarcbies Parlamentaires, París, 1960, págs. 362 y sigs. 
titular, poco entusiasta de los equipos parlamentarios, asumió la tarea de ocuparse de la defensa del reino, desde la concepción estratégica (noción del «reducto nacional») a las medidas coyunturales (eliminación de las barreras antitanques en la frontera sur en la primavera de 1940), hasta llegar al mando en jefe en el combate. Si el éxito hubiera acompañado a Leopoldo III o si en lugar de capitular y constituirse prisionero hubiera dirigido la resistencia armada en el exilio, los poderes militares del rey de los belgas no hubieran sido puestos en cuestión tras la liberación. Pero incluso después de la guerra, y resuelta la ya «cuestión real», la continuación de las coaliciones entre 1954-1958 fomentaron una situación en la que la autoridad regia en materia de defensa continúa siendo incontestada, si bien se insiste en que su ejercicio se ajuste a los cauces constitucionales. El carácter pluricomunitario de Bélgica ha contribuido también a potenciar esta función integradora de la Corona.

Entre las Repúblicas, la práctica constitucional finesa, donde el jefe del Estado ha tenido una fuerte intervención en proporción inversa a la coherencia de las mayorías parlamentarias, avala esta interpretación. En Finlandia, como en Bélgica, esta forma de parlamentarismo multipartidista y de Gobierno minoritario ha contribuido a fortalecer el protagonismo del jefe del Estado, verdadero monarca electivo, en los asuntos exteriores y en la defensa nacional ${ }^{15}$.

En conclusión de lo dicho puede afirmarse que si toda Monarquía democrática ha de ser hoy en Occidente una Monarquía parlamentaria donde «el rey reina pero no gobierna», el parlamentarismo, especialmente el de coalición, no favorece la concentración de poderes militares en el presidente del Gobierno. Antes al contrario, el ejecutivo bicéfalo (jefe del Estado y jefe del Gobierno) permite su distribución entre un jefe del Estado de carácter apartidista y formación militar y un Gobierno responsable ${ }^{16}$.

Precisar el cómo de esta distribución obliga, en primer lugar, a distinguir entre el empleo y la gestión de las fuerzas militares y, en segundo término, a examinar el significado del refrendo ministerial.

Por empleo se entiende las decisiones relativas a la utilización estratégica de las Fuerzas Armadas. Por gestión, la organización y actividades administrativas que permiten el mantenimiento de dichas fuerzas en estado tal que su utilización sea posible. Mientras el empleo es objeto de una actividad eminentemente técnico-política cuyo único cauce de dirección no es otro que el mando supremo, la gestión de las Fuerzas Armadas es una actividad eminentemente político-administrativa. En una como en otra intervienen diversos elementos, desde la jerarquía estrictamente militar a los órganos administrativos específicamente castrenses y de competencia genérica. Pero lo que interesa destacar aquí es que la experiencia comparada demuestra la intervención del jefe del Estado, ya monárquico ya republicano, en uno y otro campo. Allí donde el rey o el presidente ejerce el mando supremo de las fuerzas militares no cabe duda de que interviene, en las formas más adelante expuestas, en el empleo de las Fuerzas Armadas. Allí donde al jefe del Estado corresponde el ejercicio de una serie de actividades de índole administrativa superior, como, por ejemplo, la

${ }^{15}$ Cf. los análisis comparativos de Duverger, Echec au Roi, París, 1978, págs. 44 y sigs.

${ }^{16}$ Senelle, La Constitution Belge Commentée, Bruselas, 1974. 
colación de los grados militares, no cabe duda de que interviene en la gestión de las Fuerzas Armadas.

Ahora bien, en un sistema parlamentario, y especialmente cuando de Monarquías parlamentarias se trata, esta intervención viene presidida por el principio general de irresponsabilidad del monarca y la correlativa exigencia general de refrendo ministerial como técnica para transferir al refrendante la responsabilidad del acto refrendado. Una interpretación tan vulgar como errónea suele considerar el refrendo como la técnica para transferir la decisión plena y exclusiva sobre lo refrendado al refrendante. En su virtud, la competencia de la autoridad refrendada sería puramente nominal y, por tanto, dicha autoridad podría ser sustituible por un mero artificio automático cuya puesta en movimiento estaría en todo caso a merced de quien ejerciera a través del refrendo, en todo menos en el nombre, la plenitud de unos poderes.

Sin embargo, la realidad que ofrece la práctica comparada y que ha sacado a luz la buena técnica jurídica obliga a concluir algo distinto: el acto refrendado es un acto complejo constituido por dos conductas, la del refrendado y la del refrendante, ambas infungibles, insustituibles e imprescindibles ${ }^{17}$. El monarca que recurre al refrendo de sus ministros no puede actuar sin éstos, que, por tanto, pueden paralizar la actividad regia necesitada de su refrendo. Sin el consentimiento ministerial el rey nada puede hacer, y ello es lógico puesto que su decisión estará en todo caso cubierta por la responsabilidad de los ministros refrendantes. Pero a la vez, sin la voluntad regia, que los ministros no pueden forzar ni sustituir, no pueden producirse aquellos actos que formalmente emanan del jefe del Estado bajo el refrendo y consiguiente responsabilidad de su Gobierno. Podrá discutirse en cada acto refrendado si se trata de un acto complejo, simétrico o asimétrico, o, utilizando la terminología italiana en la materia, igual o desigual, según la voluntad regia y ministerial se equilibren o una de ellas predomine. Pero es claro, en todo caso, que cualquiera de las dos voluntades concurrentes pueden imposibilitar la realización del acto, puesto que éste requiere la concurrencia de ambas. El rey, como los ministros refrendantes, tienen lo que Barthélemy ${ }^{18}$ denominaba un "poder de impedir», y es doctrina usual en el mundo anglosajón que el jefe del Estado tiene obligación de impedir por la negación de su imprescindible intervención aquellos actos que atentaran a los valores, ya formales ya materiales, que la Constitución pone a su cuidado ${ }^{19}$.

En consecuencia, y trasladando estas categorías al tema que nos ocupa, es claro que el monarca parlamentario no puede ejercer el mando militar sin la asistencia ministerial que endosa la responsabilidad de los mismos. Por ello fue perfectamente constitucional la conducta de Alberto I e inconstitucional la de Leopoldo III, porque la primera contó con la asistencia, al menos formal,

${ }^{17}$ Cf. Donati, Atto Complesso, Autorizzazione, Aprovazzione, en Archivio Guridico, LXXI, 1903, pág. 11. Sobre esta cuestión, que trataré más ampliamente en otro lugar, existe una amplia bibliografía analizada por Biscaretti, La Proposta nel Diritto Pubblico, Roma, 1936, págs. 63 y sigs., ampliada en las posteriores ediciones de su Derecbo constitucional.

${ }^{18}$ Le Gouvernement de la France, París, 1919, pág. 93.

39 Gledhill, The Republic of India, Londres, 1951, comentando el artículo 53 de esta Constitución. 
de su Gobierno y el segundo despreció la del suyo. Dicha asistencia puede expresarse en el refrendo del ministro o ministros responsables de las órdenes del rey o puede consistir en cualquier otra expresión de conformidad con los actos del rey, por ejemplo, la mera presencia física junto a éste. Pero no es menos cierto que el ejercicio del mando militar en estas condiciones no equivale a una actividad puramente formal carente de contenido y compatible con la competencia exclusiva de los ministros en la materia, puesto que si el rey necesita el concurso de éstos, la actividad refrendada o de cualquier manera endosada por éstos sigue siendo una actividad regia. Obviamente ello es válido tanto para el ejercicio efectivo del mando militar como para su ejercicio meramente simbólico y la delegación o avocación del mismo mediante, por ejemplo, el nombramiento de un comandante en jefe.

Lo mismo puede decirse de las actividades administrativas superiores, mediante las cuales el jefe del Estado toma parte en la gestión de las Fuerzas Armadas. Por ejemplo, la colación de empleos y destinos militares. En estos casos el rey ejercerá poderes discrecionales o reglados. Como ejemplo de los primeros puede citarse la colación de un destino. Como ejemplo de los segundos la promoción a un empleo. En ambos casos la actividad del rey requiere articularse en un acto complejo con la actividad ministerial, de manera que sin ésta aquélla no es eficaz. Pero ello no debe ocultar que sin voluntad regia, que el refrendo completa pero que en ningún caso sustituye, el acto en cuestión es imposible.

Con ocasión de la resolución de la cuestión real en Bélgica, una Comisión nombrada al efecto emitió un dictamen sobre «La aplicación de los principios constitucionales relativos al ejercicio y prerrogativas del rey y a las relaciones de los grandes poderes constitucionales» ${ }^{20}$. Este dictamen pasó por ser en el mundo continental, como muchos decenios antes la propia Constitución belga de 1831, el paradigma de una monarquía constitucional, y hoy es todavía la mejor sistematización, aparte del mundo anglosajón, regido por principios muy análogos, y de los casos exorbitantes de Suecia y Japón antes mencionados, de la espina dorsal de la monarquía parlamentaria en la práctica. Según las decisiones mayoritarias de la Comisión, el rey no puede en ningún caso actuar solo, de manera que «todo acto del rey susceptible de tener una incidencia política directa o indirecta debe estar endosado por un ministro» (cap. I, parágrafo II). Sin embargo, «la función del rey no es puramente pasiva, y el acto regio, en el sentido constitucional del término, surge del concurso de la voluntad del ministro con la del rey. De esta manera se encuentran asociados en el ejercicio del poder el rey, que permanece por encima de los partidos, y el Gobierno que se apoya sobre la mayoría del Parlamento» (cap. I, parágrafo III).

Aunque, y ello es opinión unánime de la Comisión, «la Corona deba siempre contar con la intervención de un tercero, el ministro refrendante, se trata de una acción conjunta» que no puede prescindir ni del rey ni del ministro, y la solución al desacuerdo entre ambos no es, según el dictamen de la citada Comisión, la sumisión del rey, sino la dimisión de los ministros (cap. I, parágrafo III).

${ }^{20}$ Moniteur Belge, 6 de agosto de 1949, págs. 7589-7600. 
Los mismos principios se aplican al mando del Ejército (cap. III) ${ }^{21}$.

No es este el lugar para analizar en toda su complejidad las relaciones del rey y el Gobierno, tema al que espero en breve dedicar una amplia obra. Baste decir que corresponde al Gobierno, no a su solo presidente, la dirección política de todo el Esstado y, por tanto, también de la defensa, según el artículo 97 de la Constitución. Pero esta dirección, en algunos supuestos, ha de articularse con las competencias «que ejerce» el rey (art. 56). Uno de estos supuestos, y no precisamente el único, es el de la defensa. Esta articulación se lleva a cabo mediante el refrendo, técnica característica de la Monarquía parlamentaria.

La Monarquía que configura nuestra Constitución de 1978 como forma de Estado es una Monarquía parlamentaria (art. 1.3), y, además de este imperativo constitucional, el mismo interés de la Corona aconseja mantenerla dentro de esta función de «reinar sin gobernar», propia del parlamentarismo coronado. Sin embargo, la Monarquía parlamentaria no es lo mismo que el parlamentarismo sin jefe de Estado, y ambas formas son muy distintas en la historia constitucional ${ }^{22}$.

Solamente la práctica comparada puede decirnos qué se entiende por Monarquía parlamentaria, y el balance de esta práctica no es la reducción del trono a «un sillón vacío». La Corona en una Monarquía parlamentaria tienen funciones que cumplir y las cumple de manera activa, aunque limitada. El desarrollo legislativo de la Constitución, como su correcta exégesis, debe por supuesto mantener esta limitación, pero sin reducir aquella actividad, única que da sentido y justifica a la propia institución monárquica. Si en su mismo interés es preciso evitar toda tentación de monarca gobernante, no es menos cierto que el vaciamiento de todas las competencias del rey y su reducción a la mera «presidencia de las solemnidades nacionales» conduce a privar a la Monarquía, incluso parlamentaria, de toda justificación. Ello es especialmente cierto en un campo tan importante y tan vinculado a la Corona por razones jurídicas y emocionales como la defensa nacional.

\section{REY, GOBIERNO Y PRESIDENTE SEGUN LA CONSTITUCION ESPAÑOLA}

En España las competencias militares de la Corona vienen establecidas en el artículo 62 de la Constitución, según el cual corresponde al rey el mando supremo de las Fuerzas Armadas.

${ }^{21}$ En los términos del artículo 68 de la Constitución «el rey manda las fuerzas de tierra y mar. Diversos puntos de vista se han manifestado en el seno de la Comisión en cuanto a la naturaleza de los poderes que esta disposición confiere al rey. La Comisión se ha dividido en dos opiniones: según una, el mando supremo de los Ejércitos puede, en una cierta medida, ejercerse fuera de las reglas de la responsabilidad ministerial; según la otra, este mando supremo debe, como todos los otros actos del rey, someterse a lo previsto en el artículo 64 de la Constitución». Loc. cit., pág. 7595. No se discute, por tanto, si corresponde al rey o no el mando supremo, lo que parece fuera de cuestión, sino si los ministros han de refrendar o no los actos de dirección militar, esto es, si el mando supremo del rey ha de ejercerse por los solos actos del rey o por actos complejos; según la tesis que se defiende en el texto.

${ }_{22}$ Así lo atisba Sánchez Agesta agudamente en Sistema político de la Constitución española de 1978, Madrid, 1980, págs. 198-199. 
La interpretación literal y sistemática de este precepto obliga a concluir que no se trata de una atribución meramente simbólica de la Corona, como podría ser el que en su nombre se ejerciera la justicia (art. 117), sino de una atribución efectiva. En efecto, el artículo 56 de la Constitución dispone que el rey «ejerce las funciones que le atribuye expresamente la Constitución y las leyes».

Se trata de una competencia tasada que excluye toda noción de prerrogativa y configura a la Corona como un poder constituido en virtud de la propia norma constitucional. El rey de España, como el de los belgas desde 1831, no tiene más poderes que los que la Constitución le atribuye, pero es claro que, en virtud del mismo argumento, tiene los poderes que la Constitución le atribuye, y la propia Constitución, después de atribuirle, en virtud de cláusulas generales, las competencias de índole simbólica, moderadora y arbitral, dispone que «ejerce las competencias que le atribuye expresamente».

Ahora bien, una de estas funciones es, según el mencionado artículo 62, el mando supremo de las Fuerzas Armadas, de modo y manera que la lectura integrada de ambos preceptos exige reconocer que el rey ejerce el mando supremo de las Fuerzas Armadas, como ocurre, según quedó expuesto más atrás, en el resto de las Monarquías europeas.

Sin duda esta competencia regia ha de ejercerse, como todas las demás, bajo refrendo, en este caso de los ministros responsables, que cubren con ello la irresponsabilidad del monarca (art. 64); pero esta exigencia de refrendo y consiguiente endoso de responsabilidad no puede interpretarse como una transferencia total de la decisión del rey al ministro refrendante, sino que exige que determinadas funciones públicas se realicen en un acto complejo donde concurren tanto la actividad del rey como la actividad del ministro. Tal es el significado teórico y práctico del refrendo en todas las monarquías. Si el rey no puede actuar sin el concurso de los ministros, el Gobierno, al necesitar la decisión regia que sirve de soporte a su refrendo, puede ser paralizado por la decisión del monarca de no actuar.

Estos son los principios constitucionales que deberá respetar la Ley Orgánica de las Fuerzas Armadas, según exige la propia Constitución (art. 8.2).

Ahora bien, el desarrollo legal de estas disposiciones constitucionales, primero en la Ley de 28 de diciembre de 1978 relativa a los Organos Superiores de la Defensa Nacional y, después, en la Ley Orgánica por la que se regulan los criterios básicos de Defensa Nacional y la Organización Militar, parece vaciar de contenido estos preceptos constitucionales, o, lo que es lo mismo, reduce a meramente simbólico el mando militar del rey y a meramente consultivo la función del Gobierno.

En efecto, según las citadas leyes y las Reales Ordenanzas aprobadas por Ley de 28 de diciembre de 1978 , al rey corresponde el mando supremo. El contenido de este mando puede ser triple. Por una parte, corresponde al rey lo que se denomina en Derecho constitucional comparado el mando eminente sobre las Fuerzas Armadas, y que es aquel que le corresponde como jefe del Estado del que esas Fuerzas Armadas dependen y que se concreta en actos de valor simbólico (por ejemplo, fórmula de juramento a la bandera) y de alto 
significado moral ${ }^{23}$. En segundo lugar, puede corresponderle el mando efectivo de las mismas, susceptible de llegar hasta la asunción del mando en jefe del Ejército combatiente. Por último, dadas las características de la guerra moderna, el mando político debe coincidir con las grandes opciones estratégicas propias del supremo mando militar, y de aquí que la comandancia en jefe de las Fuerzas Armadas del jefe del Estado revista una especial utilidad cuando pueda concretarse en las decisiones supremas que comprometen irreversiblemente a la nación y su propia existencia.

Sin embargo, de los artículos 10, 11 y 12 del Proyecto de Ley de la Defensa Nacional parece deducirse que el mando efectivo de las Fuerzas Armadas corresponde a los jefes de los Estados Mayores de los tres Ejércitos coordinados en su Junta de Jefes de Estado Mayor bajo la autoridad del ministro de la Defensa, cuya autoridad es a su vez avocable por el presidente del Gobierno. Así, se dispone que «los jefes de los Estados Mayores del Ejército de Tierra, de la Armada y del Ejército del Aire ejercen el mando militar de sus respectivos Ejércitos bajo la autoridad del ministro de Defensais (art. 12.1), y en este sentido abundaba la propuesta socialista de convertir a dichos oficiales generales en comandantes generales del Ejército de Tierra, la Armada y el Ejército del Aire respectivamente.

Por otro lado, el alto mando, como competencia para las grandes opciones estratégicas, se reserva en exclusiva al presidente del Gobierno, según el artículo 8.2, que, atendiendo a su tenor literal, excluye toda intervención del jefe del Estado en la dirección de la guerra una vez que esta competencia se configura como propia y exclusiva del presidente del Gobierno.

Sin duda este artículo supone una extralimitación respecto de lo previsto en la propia Constitución, puesto que si algún otro órgano, a más del rey, tiene competencias rectoras en materia de defensa, es el Gobierno, a quien corresponde dirigir la defensa del Estado (art. 97), y si bien el presidente dirige la acción del Gobierno (art. 98.2), una cosa es dirigir la acción de un órgano colegiado y otra es asumir de manera exclusiva las competencias de dicho órgano o la medula de las mismas. ¿Cómo puede el Gobierno dirigir la defensa de la nación si el presidente ejerce la dirección de la guerra? La mera determinación de la política de defensa prevista en el artículo 7 de dicha Ley como competencia gubernamental no cubre todo el campo que al Gobierno atribuye el artículo 97 de la Constitución.

Queda en consecuencia al rey tan sólo el alto mando eminente, ajeno a toda competencia política y militar, reducido a meras presencias simbólicas y morales y bajo la dirección política del presidente del Gobierno, lo que contradice toda lógica e incluso la propia función neutral de la corona. Con ello, el desarrollo legal de la Constitución intenta realizar una profunda mutación del sistema previsto en la misma y que se aparta notablemente del derecho y la práctica vigentes en la mayoría de las Monarquías e incluso de las Repúblicas parlamentarias europeas.

Mientras la Constitución prevé que tanto en el empleo como en la gestión

${ }^{23}$ Sirve de ejemplo la presencia de Víctor Manuel III de Italia en el frente Norte en 1917. 
de las Fuerzas Armadas el jefe del Estado, como su comandante en jefe, realiza a través de actos complejos, esto es, con el refrendo de sus ministros, importantes actividades o, lo que es lo mismo, la Constitución configura la defensa nacional como una competencia compartida del rey y del Gobierno, atribuyéndole al rey la posición a la que corresponde la adopción bajo refrendo de las decisiones supremas, la Ley bace de la defensa nacional una competencia exclusiva no ya del Gobierno, sino del presidente del mismo.

Se ha pretendido justificar esta solución afirmando la necesidad del sometimiento del poder militar al poder político y la atribución de éste al Gobierno responsable, y más concretamente a su presidente, como figura clave del mismo. Sin embargo, no es esta la solución que ha prosperado en los sistemas parlamentarios, y menos aún en las Monarquías parlamentarias en las que el jefe del Estado, como elegido de toda la nación, y más aún como designado por la historia de la nación, corresponde representar el conjunto integrado de la misma frente a quien, en el mejor de los casos, es tan sólo el jefe de una mayoría y en el más común de los supuestos, y más concretamente en el caso español, el jefe de una minoría coaligada con otras fracciones aún menores.

En las Monarquías parlamentarias corresponde al monarca el mando de las Fuerzas Armadas no sólo en forma simbólica, sino con un notable grado de efectividad, y las condiciones técnicas de la guerra moderna permiten que esta atribución nominal de la Constitución llegue a ser tan efectiva como cuando el soberano asumía personalmente el mando de las tropas, todo ello sin perjuicio de que cada uno de los actos del alto mando del rey deban estar cubiertos por la responsabilidad de su Gobierno, esto es, deba hacerse de acuerdo con el Gobierno, algo muy distinto de por sólo el Gobierno. Y más todavía por sólo el presidente del Gobierno.

Sin embargo, lo que ha prosperado en la Ley es una solución, consciente o inconscientemente inspirada de manera muy directa de la experiencia fascista italiana, en la que, por imperativos ideológicos del fascismo, la dirección política y militar de la guerra debía coincidir en la persona del Duce, de la que los organismos militares eran meros asesores y al que el rey transfería sus facultades de alto mando. La configuración de la Junta de Defensa Nacional y la hipertrofia de la competencia militar del presidente del Gobierno que lleva a cabo la Ley Orgánica se corresponden exactamente con la organización que a la defensa militar de la Italia fascista diera la Ley de $1938^{24}$.

Por ello, el segundo párrafo del artículo 8 de dicha Ley puede y debe considerarse inconstitucional, contrario tanto al artículo 62 en relación con el 56, relativo a las competencias del rey, como al artículo 97 , referente a las competencias del Gobierno.

\section{LA FUNCION DE LAS FUERZAS ARMADAS}

La jefatura de las Fuerzas Armadas por parte del rey tiene otro alto significado constitucional atendiendo a la función de las propias Fuerzas Armadas.

${ }^{24}$ Cf. Valori, La Condotta Politica della Guerra, Milán, 1934, pág. 243. Cf. Real Decreto 8 de julio de 1938, núms. 14-15, y la Proclama Regia de 11 de junio de 1940 . Sobre los aspectos jurídicos de la cuestión, Pierandrei, loc. cit., págs. 43 y sigs. 
Según el artículo 8 de la Constitución, éstas tienen como misión «garantizar la soberanía e independencia de España, defender su integridad territorial y el ordenamiento constitucional», y tanto las Reales Ordenanzas, en su artículo 3 , como la Ley Orgánica de las Fuerzas Armadas, en su artículo 2, reiteran esta misión de las Fuerzas Armadas como institución.

Ahora bien, el rey es parte integrante de las Fuerzas Armadas, constituidas por el Ejército de Tierra, la Armada y el Ejército del Aire «bajo el mando supremo del rey» (art. 2 de las Reales Ordenanzas), de cuya realidad hay testimonio en las propias Ordenanzas (art. 201). En consecuencia, el rey, como comandante en jefe de dichos Ejércitos, y a ello responde su empleo de capitán general, es también, y como tal, responsable institucional del ordenamiento constitucional.

¿A dónde llega esta responsabilidad? Mientras las instituciones del Estado funcionen regularmente, al monarca corresponde su moderación, según el artículo 56 de la Constitución. El arbitraje regio previsto en el mismo artículo 56 sirve para garantizar dicho funcionamiento regular, aunque está claro que el arbitraje frente a la moderación trasciende y se sobreordena al funcionamiento de las propias instituciones. Pero en todos estos supuestos la garantía que al orden constitucional prestan las Fuerzas Armadas es meramente latente y potencial y no se actualiza y hace patente hasta que dicho funcionamiento regular entra en crisis.

El funcionamiento normal de los poderes públicos supone su capacidad de autorregularse; piénsese, por ejemplo, en la sustitución de un Gobierno por otro a través de la moción de censura constructiva aprobada por el Congreso de los Diputados, y en este caso el rey ejerce tan sólo su competencia de aconsejar y advertir. $\mathrm{El}$ arbitraje regio interviene precisamente cuando este funcionamiento regular exige algo que le trasciende; piénsese, por ejemplo, en la disolución de las Cortes o en la designación tras nuevas elecciones de un candidato a presidente del Gobierno susceptible de recibir la investidura parlamentaria. Pero en todos estos supuestos es innecesaria la intervención militar.

Ahora bien, precisamente la garantía militar del ordenamiento constitucional, como su garantía de la integridad territorial del Estado o de la unidad nacional, pasa de virtual a actual cuando este ordenamiento constitucional se encuentra de tal manera amenazado o su funcionamiento perturbado que no bastan ni su capacidad de autorreglaje, ni la moderación ni el arbitraje regio, es decir, cuando son las propias instituciones quienes se encuentran amenazadas o interrumpido el funcionamiento regular de los poderes públicos. Una vez más la fuerza, que trasciende al Derecho, es la última garantía del mismo: ultima ratio leguum, la última razón de las leyes. Ahora bien, si la Constitución prevé que las Fuerzas Armadas son para tales ocasiones la garantía del ordenamiento constitucional, es claro que el rey, parte, y parte muy principal de ellas, ha de cumplir también aquí su función constitucional de jefe supremo de aquella institución armada que asume la garantía política última de la Constitución, y a ello parece comprometerse cuando jura, como la Constitución exige que lo haga, «guardar y hacer guardar la Constitución» (art. 61.1). Si todas las autoridades han de guardar la Constitución y las Leyes y hacerlas guardar en el ejercicio de su competencia, el rey, que modera y que arbitra, 
se compromete también a defender activamente el ordenamiento constitucional; y los valores materiales en él implícitos, en ejercicio del mando militar que la propia Constitución le atribuye. Para ser eficaz, la ultima ratio leguum ha de ser ultima ratio reguum, la última razón de las leyes ha de ser última razón de los reyes ${ }^{25}$.

El Estado de Derecho se caracteriza por someter todo poder a una previsión legal, y de ahí la regulación constitucional de los Estados de excepción, consistentes en habilitar un margen de discrecionalidad para hacer frente a situaciones de anormalidad. Sin embargo, los diversos regímenes de excepción que la Constitución prevé y que puede prever, por ejemplo, la española en el artículo 116, son situaciones que no empecen un regular funcionamiento de los poderes públicos capaz de hacerles frente ${ }^{26}$.

Por el contrario, existe una posible excepcionalidad allende este funcionamiento regular de las instituciones cuando la subversión o la agresión externa ponen en peligro la existencia misma del aparato del Estado; tal es el supuesto a que responde la vieja dictadura romana y que ha sido contemplada por sus modernos teóricos. Así, por ejemplo, el Estado de sitio contemplado en nuestra Constitución (art. 116.5) supone el normal funcionamiento del Congreso de los Diputados. Pero, ¿qué ocurre cuando este funcionamiento está en quiebra? ${ }^{27}$. Ante esta eventualidad, la Constitución francesa de 1958 previó, por encima de otras situaciones de excepción, la dictadura constitucional del jefe del Estado, competente en ejercicio de la misma para disponer, entre otras cosas, también de las Fuetzas Armadas. El constituyente español de 1978 no siguió este camino, sino que atribuyó a la institución militar la competencia última para, en situaciones semejantes, garantizar la integridad nacional y el orden constitucional. Esta disposición no puede ser mera retórica, es nada menos que «la invocación al guerrero». Ahora bien, esta «invocación del guerrero» para ser coherente ha de serlo con todas sus consecuencias, esto es, a las Fuerzas Armadas, que, según rezan las Reales Ordenanzas, «forman una institución disciplinada, jerarquizada y unida» (art. 10) «bajo el mando supremo del rey» (art. 2).

En este supuesto, reducir la previsión constitucional y legal a mera retórica

${ }^{25}$ Según el citado dictamen belga, «el juramento del rey consagra la existencia de un deber fundamental que determina la interpretación a dar al artículo 68». En una República con una jefatura de Estado muy débil, la República Federal Alemana, la misma interpretación se ha dado al juramento del presidente, previsto en el artículo 56 de su Ley Fundamental, en el sentido de que se convierte en defensor de la Constitución por jurar o prometer «guardarla y defenderla» (cf. Die öftentliche verwaltung, 1949, págs. 272 y sigs.).

${ }^{26}$ Cf. Serrano, «Situaciones excepcionales y fuentes del Derecho en la Constitución española de 1978», en La Constitución española y las fuentes del Derecbo, III, Madrid, 1979, págs. 1957 y sigs. En el mismo sentido, Camus, L'Etat de Necessité en Democratie, París, 1965, y Leroy, L'Organisation Constitutionnelle et les crises, París, 1966.

${ }_{27}$ Tal es la tesis de Schmitt en sus famosas obras sobre La dictadura y La defensa de la Constitución (1928), y hoy es usual en la interpretación francesa del artículo 16 de la Constitución de 1958. Pese a las tesis decisionistas de Schmitt, la defensa política de la Constitución no empece su tutela jurídica, en España a cargo del Tribunal Constitucional como en Francia del Consejo Constitucional. Esta compatibilidad de ambas defensas a cargo del Tribunal y del Ejército fue expresamente mantenida por García Pelayo al inaugurar el primero. 
es dejar vacío de contenido el significado del juramento regio y a la vez entregar la garantía de la Constitución no a quien simboliza su unidad y permanencia, sino a unos eslabones fraccionarios de la cadena jerárquica que si bajo el mando del rey se integran en el Estado, desconectados del mismo o al servicio del jefe accidental de una minoría política - y este es necesariamente el caso del jefe del Gobierno-, son simplemente sus pretorianos. Si en situación de crisis el jefe del Estado no es el jefe del Ejército, serán los jefes del Ejército quienes asuman la jefatura del Estado, y no faltan experiencias históricas y contemporáneas que avalen esta interpretación. Pero precisamente para que el rey en situación de crisis pueda ser jefe del Ejército es preciso que en la más habitual y deseable situación de normalidad sus competencias constitucionales en este sentido no se conviertan en palabras vacías.

\section{CONCLUSION}

Como conclusión de todo lo expuesto pueden formularse las tres tesis siguientes:

En primer lugar, el mando supremo de las Fuerzas Armadas, que constituye una dirección propiamente política de las mismas tanto en tiempos de paz como de guerra, corresponde al rey bajo el refrendo y la responsabilidad del Gobierno. Sin duda, este mando supremo puede reducirse al meramente eminente y simbólico o ampliarse hasta la dirección efectiva de las fuerzas en combate, si bien en la situación actual ello no es siempre recomendable. Tamhién podrá variar, según las circunstancias, la cuota que de hecho corresponde al rey o al Gobierno en las decisiones efectivas. Sin embargo, dicha cuota deberá nermanecer en el más estricto y reservado de los secretos y el mando supremo será siempre una actividad regia y la responsabilidad siempre una responsabilidad ministerial. En consecuencia, el mando supremo, como suprema dirección política, se ejercerá mediante actos únicos, esto es, actos que constitucionalmente lo son del rey y cuya génesis supone la concurrencia de la voluntad regia y la voluntad ministerial, expresada en forma de refrendo o equivalente. Resumiendo, se tratará de actos únicos pero complejos.

Otro tanto ocurre en lo que a la gestión de las Fuerzas Armadas se refiere, según lo previsto en el artículo 62 de la Constitución respecto de la colación de los empleos militares.

Corresponde al Gobierno el resto de la administración militar.

En segundo lugar, puede afirmarse que, en la medida en que no se atiene a estos principios, la reciente Ley Orgánica reguladora de las Fuerzas Armadas es inconstitucional y los preceptos de la misma que están en contradicción con lo previsto en la Constitución -concretamente el artículo 8.2- no deben primar sobre aquélla - los artículos 62 y 97-, puesto que la Constitución es una norma de rango superior cuya prioritaria vigencia se deduce del principio de jerarquía normativa afirmada en su artículo 9 como base de nuestro ordenamiento jurídico.

Por último, debe señalarse la peligrosidad de realizar un desarrollo constitucional que transmute el sentido de la parte orgánica de la Constitución, 
vaciando de competencias a la Corona y, paralelamente, también al Gobierno, construyendo un sistema neopresidencialista incompatible con la literalidad de la Constitución y con el espíritu de la Monarquía parlamentaria y del sistema de gabinete a que dicha Constitución responde. Sin duda, una democracia moderna se caracteriza por un fuerte liderazgo, y el primer ministro pasa de ser un primus inter pares a un jefe del ejecutivo nacional, transformándose el Gobierno, órgano colectivo, de ser colegial en ser complejo, de manera que la figura del presidente adquiere una propia sustantividad y una jerarquía superior a la de los demás miembros del Gobierno. Sin embargo, ello no puede llevar sin quebrar totalmente el sistema constitucional vigente a configurar la presidencia del Gobierno como un órgano monocrático del que los demás ministros son meros vicarios ${ }^{28} \mathrm{y}$ el jefe del Estado un instrumento.

${ }^{28}$ Sobre la distinción entre órganos colegiales y complejos, cf. Crossa, Diritto Constituzionale, Turín, 1957, pág. 14. 